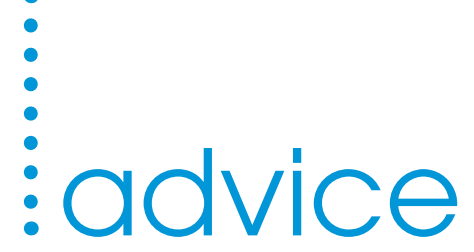

\title{
Restoring harmony to dental practice
}

The Dental Complaints Service was set up in 2006 and has proved highly successful. Head of the Service, Hugh Smith, explains how it works.

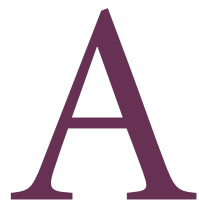

11 dental practices should have an effective complaints handling procedure with which every member of the dental of your patients remins disstisfed, even af your patients remains dissatisfied, even after his or her complaint has been reviewed by you, what then? For many years, NHS patients have been able to turn to the NHS complaints scheme to help them resolve outstanding complaints.

\section{'The Service}

\section{aims to restore,} maintain and develop your relationship with your patients.'

Now, for patients receiving private dental care, there is the Dental Complaints Service. Of course, as professionals, we all hope to do a competent and conscientious job. But inevitably things sometimes go wrong.

The aim of the Dental Complaints Service is to help patients and dental professionals resolve complaints about private dental treatment or service, and ideally to restore, maintain and develop your relationship with your patients.

Although launched and funded by the General Dental Council, the Service, with its own staff and office, operates independently of the UK dental regulator and its fitness to practise procedures, which continue to consider issues of patient safety.

Through the Service, patients across the UK can complain about any aspect of private dental care, involving any member of the dental team, including those members who have newly registered with the GDC: dental technicians, clinical dental technicians, dental nurses and orthodontic therapists.

We try to help resolve complaints as fairly, efficiently, transparently and swiftly as possible. Indeed, we have had several examples of dental professionals seeking our assistance to resolve long-standing or problematic complaints, and we welcome this.

Feedback from professionals tells us that the Service provides a useful 'next step' for the unsatisfied complainant, who otherwise might take their complaint to the courts, or - if they decide not to pursue the complaint - take their business elsewhere.

So the Dental Complaints Service can assist you in managing complaints more positively and effectively, helping you to maintain and improve your relationships with patients. Patients, for their part, no longer need to turn to other daunting and sometimes inappropriate ways to pursue their complaint, such as legal proceedings, which can be prolonged, adversarial and expensive, for you as well as them.

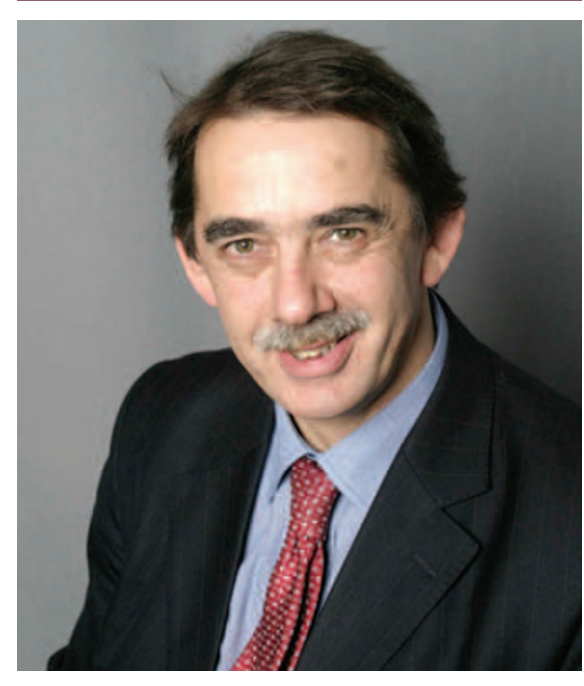

Hugh Smith, Head of the Dental Complaints Service

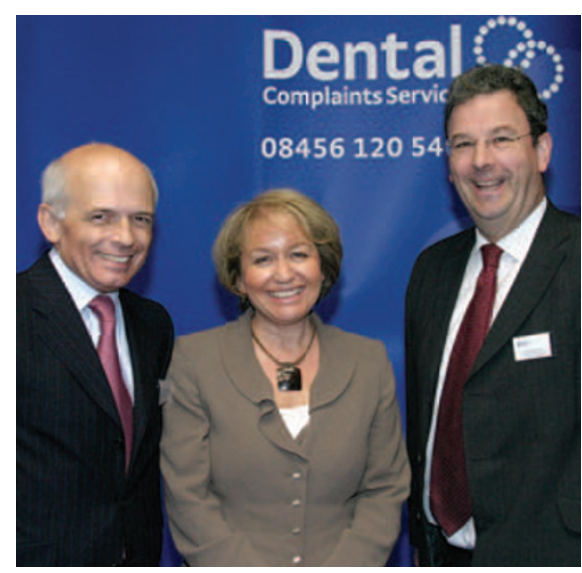

The launch of the Dental Complaints Service. From left to right: Derek Prentice, Chair; Rosie Winterton, Health Minister; Hew Mathewson, GDC President 
